\title{
A potential research direction for didactic classroom studies
}

\author{
Christina Osbeck \& Åke Ingerman
}

This essay, then, interrogates the idea of didactic classroom studies as a research direction as it is found in the essays in this volume. With an analysis of the similarities and differences between the essays in certain specific respects-research questions, theoretical and analytical framing, and the character of and connection to didactical traditions-we chart the variations and commonalities across the contributions, and from that go on to formulate suggestions for the further development of this research direction. The underlying claim in this approach is thus that the studies in this volume-with its limitations in terms of fully reflecting didactic classroom studies and the authors being based at the same university, albeit with different specialisations-together comprise an interesting case of variation, which on reflection will provide the means with which to address the challenges of didactic classroom research and to find a way forward as a potential research direction.

\section{Didactic classroom studies}

In articulating didactic classroom studies as a research direction, we first characterise the situations our research focuses on, and from that formulate a broad research question that functions generatively and distinctively for the research direction. 
The first characteristic of didactic classroom studies is its focus on the classroom as an arena for organised teaching and learning. The classroom is in most cases one or a limited set of specific physical locations in school designated for teaching and learning. At the same time, it is not the physical layout that primarily makes a classroom a classroom. It is the organised activity of teaching and learning that makes a classroom into an intentional practice that teachers and pupils meaningfully engage in. Classrooms are an important social arena for these actors, with societal impact; however, from a didactical perspective, the interest in the classroom can be understood as focused on the core activity of teaching and learning. This is a multilayered interest, where "The term "teaching" focuses on the activity of teachers. At the same time, it presupposes a relation to a person taught (or often a group of persons), and in this sense refers to a social phenomenon. [...] The fundamental character of teaching concerns the relation between what the teacher does and the learning environment on one hand, and the result as expressed by the learner(s) on the other hand' (Svensson 2016, 276). The present studies share a clear empirical concern with the classroom and its activities, but also a systematic, scientific character. They represent a spectrum of theoretical and analytical stances, empirical contexts and scales, but they nevertheless share a common connection to the heartlands of didactics.

The second characteristic of didactic classroom studies concerns didactics. Didactics as a field has a common core (Hopmann 2007; Hudson 2007) of considering teaching and learning as intentional, and simultaneously having autonomy, both as autonomy for teachers and pupils, but also as autonomous activities per se-having a non-determinate character, because they are unfolding events. This equates to a firm conviction that the professional, committed teacher is at the heart of successful schooling (in line with many studies outside didactics as summarised by Hattie 2009 and others), and that teaching that facilitates pupils' intellectual engagement, both immediate and continuous, is associated with positive learning outcomes (see, for example, Freeman et al. 2014). The teachers' professional facilitation of pupils' engagement is part of the common 
core of didactics: a commitment to Bildung. It also points to what is acquired in the classroom: the educative constitution of meaning from the subject matter (of teaching). In this way, the teacher, the pupil, the content, and their relationships as manifested in teaching and learning together constitute the core focus of didactics, which is also expressed in the didactic triangle.

\section{Contextual didactic classroom studies}

A specific advantage with didactic classroom studies is that they are able to focus on teacher and pupil interactions around specific content taught and learnt in a specific context. In the classroom, these complex, contextual interrelationships are dynamically shifting, interacting, and folding in on themselves in both the short and long term. Even if the contextual character of teaching and learning is implied in didactic classroom studies, it is important to stress that drawing conclusions without clear links to contextual factors can easily go awry. We point to two main groups of such contextual factors. One group is situational, temporally shifting, and individual factors. The other group is underlying structural factors in the physical, temporal, and social organisation of the classroom, which are not explicitly attended to in the classroom. Even though both these groups of factors are ingrained in events and constituted meaning, they are in themselves not the primary knowledge interest in didactic classroom studies. However, the complexity that classroom studies makes visible also means that a strongly reductionist research approach can be avoided. Didactic classroom studies focus on wholes of teaching and learning, as argued by Svensson (2016), recognising that relevant phenomena of teaching and learning are inextricably intertwined. This means that these contextual and complex reflections, from a systematic and scientific stance, can ensure the results being both directly useful in practice and firmly based in (educational) science, thus remaining true to the potential for didactics to be a teachers' professional science (Ingerman \& Wickman 2015). 


\section{Didactical consequences for classroom teaching}

Didactic classroom studies examines classrooms for aspects that can be theorised, using components already established in the field of didactics. The studies concentrate on teaching and learning activities and educational events in the classroom. Such events have a direction, which necessitates a recognition that later events are shaped by teachers' and pupils' intentional actions. As Klette argues, the relational dynamics are not well understood and 'There is a need for more integrated frameworks that link instructional activities and procedures (the how) with thematic patterns (the what) and modes of interaction (the who) patterns' $(2007,148)$. Contributing to the development of such an integrated framework seems a worthwhile ambition for didactic classroom studies.

Following Klette's proposed interlinking, we identify didactical consequences as a concept of core interest. The focus on consequences highlights any attempts to relate outcomes or later events to earlier events along this chain of events and outcomes that are didactical in nature. This may be done in terms of the teacher's intentions, or in terms of possibilities or consequences for pupils' intellectual engagement with their educational progress towards Bildung on the individual level. There are two main directions that are relevant to follow here. The first concerns the direct outcomes of classroom events in terms of pupil learning. The second concerns how intentions, conditions, or previous actions constrain or open up for further didactic action. Teachers' didactical actions and choices largely determine the course of events, and the how, the what, and the who. They shape classroom situation structures and overarching conditions (for example, time limits, group size, communicative patterns, available artefacts, and curriculum) that may impose limits on subsequent didactical choices. It is not the structures themselves that are worth describing, although that would be a perfectly valid exercise; instead, it is the structures' didactical consequences for the situation in question.

The focus on didactical consequences also opens up for discussions about potential didactical actions based on the empirical patterns and the results of didactic classroom studies. New teaching situations 
may arise when we learn from previous outcomes. Didactical consequences are best understood as an analytical trope, pointing to when processes are investigated and how different parts relate and depend on one another. Contextual dependency and the small scale of the studies often mean that conclusions about consequences are tentative, but it remains important to identify the relationships and consider their meanings.

The studies in the present volume tackle didactical consequences in a variety of ways. For example, Kullberg and Skodras look at pupil outcomes in terms of examples used (a core aspect of didactics in the mathematics classroom) and Osbeck looks at the didactical consequences of a discourse established in different classrooms in terms of both pupil outcomes and possible lessons. Ingerman and Booth consider the pathways that student discussions may take as a consequence of a variety of tutor interventions; Rocksén, the different ways in which the teacher 'listens' to the pupils, and the consequences for subsequent didactical choices. Lilja and Claesson look at how relationships may constrain or enable teacher didactic action, particularly in terms of discipline. Didactical consequences are similarly the focus of Hipkiss's investigation of classroom designs.

These are the grounds for suggesting that didactic classroom studies-a scholarly enquiry into didactical intentions, choices, and conditions in the classroom, and their interactions and consequences-form a distinct research direction. The key components can be phrased as an overarching research question: What are the didactical consequences for classroom teaching and learning of the specific conditions, structures, events, contents, and teacher and pupil priorities and their various interrelationships?

This question has the great advantage of acknowledging the contextual nature of teaching and learning, and therefore the importance of keeping relationships between teacher, learner, and content intact within the study, even though the emphasis necessarily varies from study to study. Thus, the set of results arising from the studies reported here attempts to provide a scientific basis for our understanding of why and how certain learning outcomes come about, and why positive conditions for the intentional relationship between teaching and 


\begin{tabular}{|c|c|}
\hline & Aims and research questions \\
\hline Osbeck & $\begin{array}{l}\text { 'concerns the kinds of communication patterns in the two class- } \\
\text { es that may contribute to an understanding of the identified } \\
\text { differences in achievement and development' }\end{array}$ \\
\hline Kullberg \& Skodras & $\begin{array}{l}\text { 'illustrate how teachers used systematic variation in and be- } \\
\text { tween examples' }\end{array}$ \\
\hline Ingerman \& Booth & $\begin{array}{l}\text { 'develop an analytical understanding of learning in small } \\
\text { groups within the research paradigm of phenomenography } \\
\text { and the variation theory [...] what constitutes the quality of a } \\
\text { group discussion in terms of what is discussed, the character } \\
\text { of the discussion, and the appropriate, effective didactical } \\
\text { framing of group discussions [...] what different approaches } \\
\text { employed by tutors can support or hinder different groups in } \\
\text { their discussions' }\end{array}$ \\
\hline Sofkova Hashemi & $\begin{array}{l}\text { 'exploring the significance of digital mediation and multimodal } \\
\text { text design for pupils' understanding of specific content, and } \\
\text { with it the role that teacher's scaffolding may have in such a } \\
\text { modified learning environment with access to digital technol- } \\
\text { ogies [...] observes how 8-year-old pupils make meaning from } \\
\text { an instructional text composed by peers on computers' }\end{array}$ \\
\hline Hipkiss & $\begin{array}{l}\text { 'discuss classroom design: how a school subject is understood } \\
\text { from its design, what teaching and learning activities take place } \\
\text { there, and how participants interact }[. . .] \text { focus on when, where, } \\
\text { and how subject-specific language is used' }\end{array}$ \\
\hline Lilja \& Claesson & $\begin{array}{l}\text { 'to find the patterns in the way teachers handle discipline } \\
\text { in their everyday teaching. [...] what teaching strategies are } \\
\text { available, and which appear to be successful' }\end{array}$ \\
\hline Kilhamn et al. & $\begin{array}{l}\text { 'to illustrate and discuss the use of classroom videos to enhance } \\
\text { mathematics education research' }\end{array}$ \\
\hline Rocksén & $\begin{array}{l}\text { 'methodological discussion of the approaches to timescales in } \\
\text { research, and illustrates a possible research approach to empir- } \\
\text { ical material that touches on the many timescales of classroom } \\
\text { interaction' } \\
\text { 'how talk in the classroom develops and how communicative } \\
\text { patterns are constructed over several lessons' } \\
\text { 'How do science teachers and pupils attain those moments of } \\
\text { mutual understanding? How is topic progression achieved? } \\
\text { How do teachers ensure continuity in the classroom communi- } \\
\text { cation with only one or two lessons per week for a given group } \\
\text { of pupils?' }\end{array}$ \\
\hline
\end{tabular}

Table 10.1. The aims and research questions of the essays in this volume. 
learning may emerge. Some studies dwell on the elements in teaching practice that have been developed for the purposes of the research (or changed to enhance the focus of research), others look at the contours of well-established practices, and yet others discuss what may constitute quality in such studies or appropriate methods to adopt.

The essays in this volume present a range of studies of immediate relevance to this research direction. In what follows, we therefore consider the full range of research questions set out in the essays, paying particular attention to their theoretical and analytical framing, empirical design, didactical tradition, knowledge claims, and ethics. By highlighting the challenges of didactic classroom studies, we hope to contribute by pointing the way forward-a potential research direction for the field.

\section{The classroom studies}

In order to describe and compare the essays' research questions, it is necessary to chart the aims and potential knowledge contribution of each of the eight. There are thus three key issues addressed in this section. First, how to interpret the essays' knowledge contributors in their didactical focus on teachers, pupils, and content? Second, to what degree is the spotlight on the relationships between these factors? And third, to what extent does the focus fall on other conditions and structures in the classroom? Based on the research questions and knowledge contributors (as we interpret them) of the essays, we have judged the degree to which each essay concentrates on these aspects (Table 10.1).

Communication patterns are the centre of Osbeck's essay and are here understood as a combination of pupils' and teachers' discussions about the teaching content. As teachers' perspectives, pupils' perspectives, and content are intertwined in this communication, it means that the interrelationship between these three aspects is very much in focus. At the same time, the complexity of the content in itself and how it is structured cannot be said to be at the centre to the same degree as in, for instance, Kullberg and Skodras's study, described below. Osbeck presents some information about the 
conditions and structures in the two classes studied, and also stresses their potential importance to the communication patterns (how long they have worked together and the number of pupils in class) but the structures are not the focus of the study as in, for instance, Hipkiss's study.

Kullberg and Skodras's essay concerns the teachers' work with mathematics education, together with the complexity of the content. The focus is on how the content is presented and the order in which examples are presented so as to demonstrate a systematic variation. In one of the studies referred to, the order of the examples originates from specific teaching material; in the second study, the pupils' perspectives have a more prominent position and in that way, the study also demonstrates that the examples given, as such, may not be sufficient for a specific pattern to be obvious to the pupils and for certain insights to be gained. The teachers' explicit demonstration of the patterns and what these patterns show, through the use of questions, communication, and notes, may be central. The interrelationship between the teachers' acts and the structure of the content is shown to be central to the pupils' understanding, although in this specific study it is the structure of the content and the teachers' use of these structures that are in the foreground. Other structures or conditions in the classroom are only touched on in passing.

The students' perspectives and their group interactions are the focus of Ingerman and Booth's essay, with a research emphasis on learning. It is the varying quality of group discussions, and the tutor's way of responding to that varying quality, that are the specific interest questions. This also means that the learning object itself-how it is addressed, interpreted, and understood-is of special interest too. The interrelationship of these factors is central, while other classroom or group conditions/structures which might influence the work are not part of the research, even if small groups can be held to be conditions for learning.

Socio-technological changes-how the requirements for multimodal reading skills among pupils have increased-are addressed in Sofkova Hashemi's essay, and in this sense classroom conditions and structures too. But the research interest in this essay is the semiotic 
choice of the pupils: their preferences and meaning-making of audio, video, and text which in itself is the subject matter of the lesson. The pupils' work and preferences are also described in relation to their communication with their teacher. This means that the research interest is high when it comes to pupils' meaning-making in relation to certain content, and a bit lower when it comes to teachers' actions, as well as conditions and structures.

In Hipkiss's essay, the classroom conditions and structure are the centre of the research. The design of the classroom is in focus, and how this design creates meanings, provides specific venues in the classroom (controlled by specific actors), and how this in turn creates a certain power and distance in the relations between teachers and pupils-with consequences for whether and how subject-specific language is used. The affordances of the classroom, as well as the influences on and interrelationship between actors and communicated meaning, is the focus of the analyses, while the pupils and the teachers are not in focus in the same sense, and conceptual tools for these descriptions are not provided.

In Lilja and Claesson's study, the teachers' relationships with the pupils in the classroom are focused on as conditions for teaching and learning. Although it takes two people to form a relationship, a particular interest is taken here in the teachers and how they constitute these relationships. Moreover, the consequences that these relationships have for discipline and order are central in this study, since they are defined as when 'the teacher and the pupils are directed towards the same object and that the pupils have the opportunity to expand their horizons', the study could be understood as also taking aspects of the content into account. Complexity of content is not part of the research focus; for instance, attention is not paid to how difficulties in being directed towards the same object may differ depending on the character of the object-for example, a detective story or water and plants, which are examples given in this essay. It can be said that a medium degree of research focus is on the interrelationship between the didactical aspects.

The research aims of the two remaining essays are concerned with research methodology. In this summary we have chosen to concentrate 


\begin{tabular}{l|l|l|l}
\multicolumn{1}{c|}{$\begin{array}{l}\text { Not in } \\
\text { focus }\end{array}$} & $\begin{array}{l}\text { In focus to a low } \\
\text { degree }\end{array}$ & $\begin{array}{l}\text { In focus to a medium } \\
\text { degree }\end{array}$ & $\begin{array}{l}\text { In focus to a high } \\
\text { degree }\end{array}$ \\
\hline Teachers (T) & AMH, SSH & $\begin{array}{l}\text { CO; AK \& CS; Ål \& SB; AL \& } \\
\text { SC; MR; CK et al. }\end{array}$ \\
\hline Pupils (P) & AL \& SC & AK \& CS; AL \& SC; AMH & $\begin{array}{l}\text { CO; SSH; Ål \& SB; MR; } \\
\text { CK et al. }\end{array}$ \\
\hline $\begin{array}{l}\text { Content (C) } \\
\begin{array}{l}\text { Interrelationships } \\
\text { (T-P-C) }\end{array}\end{array}$ & CO; AMH & $\begin{array}{l}\text { SSH, AK \& CS; Ål \& SB; MR; } \\
\text { CK et al. }\end{array}$ \\
\hline $\begin{array}{l}\text { Conditions \& } \\
\text { structures }\end{array}$ & Ål \& SB; AK \& CS; SSH & CO; CK et al. & $\begin{array}{l}\text { CO; Ål \& SB; AMH; MR; } \\
\text { CK et al. }\end{array}$ \\
\hline
\end{tabular}

Table 10.2. The extent to which the essay's focus is the teachers, pupils, content, interrelationships, or conditions and structures. The essays are labelled with the initials of the author(s).

on the studies the authors refer to in their second-order methodological research. Both Rocksén's and Kilhamn et al's essays are based on comparisons of video data. For the former, there are many recordings from the same classroom; for the latter, the recordings are from several classrooms. Both consider the structure of the classrooms; however, Rocksén's contribution does so to a greater degree, since the timescale is one of the most central factors that the study uses when examining the development of communication patterns. Kilhamn et al's overarching focus is the organisation of classroom work as a central structuring factor, but they also have other central research objects, such as teacher perspectives and the pupils' ability to make use of experiences from one problem-solving context in another context. By focusing on educational communication patterns in the classroom, as both essays do, both teachers' and pupils' utterances about content are found to be of importance, as is the interrelationship between these aspects. In both studies, the communication patterns concern content, and the research interest in this respect is in-depth in character.

The research focuses of this volume can be set out in tabular form (Table 10.2). It demonstrates one of the hypotheses that has driven this present project, namely that classroom studies to a large extent 
develop knowledge about teachers, pupils, and content in interrelational senses - they realise the ambition of designing didactic studies with distinct consequences for teaching and learning, understood as necessarily involving certain meanings and content. Furthermore, it may also be noted that the kind of content focused on in these studies is confined to the specific classroom episodes studied. Certain content themes and how these are dealt with, rather than school subjects as such, or different conceptions of school subjects (for example, Englund \& Svingby 1986; Lindmark 2013) are the focus.

Evidently, there are not large differences in the extent to which the factors of interest are addressed in the essays. Despite this, it seems as though the teacher is the factor that is emphasized most frequently. Given that didactic studies often have an interest in the learning intended by teaching, and teachers' actions can be understood as strategies to ensure particular learning outcomes, this could be thought as a reasonable finding.

The factor paid least attention is classroom conditions and structures. If teaching and learning can be understood as contextual, and structures such as the design of the classroom have the kind of impact that Hipkiss's essay indicates, this is a noteworthy finding. This means that the classroom to a large extent is the place and space where teaching and learning are in progress, and that research is being conducted without paying sufficient attention to what this context means, and how it differs from or resembles the contexts of other similar studies. A substantial interest in classroom conditions and structures would seem to be a priority for the further development of didactic classroom studies as a research direction.

\section{Theoretical and analytical framing}

The kinds of theoretical and analytical frameworks that the essays draw on differ (Table 10.3), and in addition the ways in which the frameworks are used varies. Nevertheless, it is common to all frameworks that they broadly address how learning (or meaning-making) is understood, how it can be enhanced (which is an important perspective in relation to teaching), and how knowledge may be 
Theoretical and analytical framing

\begin{tabular}{ll}
\hline Osbeck & Sociocultural perspective \\
Kullberg \& Skodras & Variation theory \\
Ingerman \& Booth & Variation theory \\
Sofkova Hashemi & Social semiotic \\
Hipkiss & Social semiotic \\
Lilja \& Claesson & Hermeneutic; phenomenology \\
Kilhamn et al. & $\begin{array}{l}\text { Socio-cultural research tradition, a dialogical approach to communication } \\
\text { Mathematical Knowledge for Teaching, MKT (Cf. Pedagogical content know- } \\
\end{array}$
\end{tabular}

Rocksén

Dialogical theories of communication

Table 10.3. Theoretical and analytical framing of the essays.

interpreted. The explicit connection to a theoretical and analytical framework is important if the studies are to be thought characteristic of scientific didactics (Öhman 2014).

In variation theory, the learner comes to discern new dimensions of variation, thereby developing the capability of experiencing the phenomenon in qualitatively different, more complex and powerful ways' (Ingerman \& Booth). A pupil's opportunities to learn can be enhanced by teaching processes in which critical aspects of the object of learning are clarified (Kullberg \& Skodras). In Rocksén's essay, teaching processes are described as 'being primarily a communicative activity'. Such an understanding is also a central perspective in the essays by Osbeck and Hipkiss, who like Rocksén, focus on the communicative patterns and collective meaning-making in the classroom, with an eye to content-specific language and its expression (in Osbeck, for example, in the form of speech genres). Due to these differences, the frameworks allow detailed analyses of various kinds, concerning different aspects of teaching and learning processes in the classroom (which are understood as essential), even if on an overarching level the frameworks can be understood as addressing similar phenomena.

The essays differ concerning the degree to which they are driven by theory or by empirical data. It is obvious in some of the theory-driven essays that it is due to such an approach that it has been possible to produce analyses of a highly systematic and specific nature (for example, 
Rocksén), which in turn is a solid basis for conclusions and further research. However, when the empirical observations are as thorough and rich as they are in these essays, it is not surprising that a knowledge contribution may emerge from the studied classroom practice which may go beyond the knowledge contribution of a previously chosen framework (for example, Sofkova Hashemi). How such empirical and theoretical knowledge interests can be combined is a challenge that these kinds of classroom studies must contend with. One apparent risk is that a theoretical framework is presented with specific concepts that are not used in the analysis, while other concepts that are not clearly presented or sufficiently anchored are used.

Besides the traditional division between theoretically and empirically driven research projects, there are also essays that have a basis in current public debate and where the project has been developed in response to such concerns (for example, Lilja \& Claesson). In educational research, there is a certain closeness between the practice, public debate, and politics that constitute the conditions for research in the field. This also brings particular challenges when it comes to clarifying the concepts that are currently in use.

Many of the theoretical perspectives researchers use are so well known to them that they are taken for granted. This is an extra challenge in didactic studies, where different types of theories may be necessary, for instance one type of theory to conceptualize learning and teaching and another to discuss central content (see, for example, Kullberg \& Skodras). In order to have full transparency, it is of course important to clarify all the theories at work.

\section{Empirical design}

The amount, sort, and representation of the data that the essays in this volume draw on vary. However all studies draw on quite extensive material (Table 10.4). Working with wide-ranging material, as is often the case in classroom studies, involves questions about its selection for closer analyses. This means that the selection and representation of data are issues that are present to a high degree during the whole research project and not only at the beginning of a study, during the 
Observational data

Osbeck

Kullberg \& Skodras

Ingerman \& Booth

Sofkova Hashemi

Hipkiss

Lilja \& Claesson

Kilhamn et al.

Rocksén
80 lessons (3 classes; 1 academic year) 4 lessons analysed and quoted from

2 studies: Study I: 5 lessons (2 referred to); Study II: 1 Learning Study processes over one academic year (2 lessons referred to)

1 physics course; 7 student groups analysed, 2 groups quoted from

1 thematic work; 6 lessons; 2 lessons analysed and quoted from 5 classrooms; 29 hours; 3 lessons quoted from

3 studies; 15 teachers, 250 days; 4 lessons quoted from

17 classrooms; 85 lessons, summaries but no single lesson quoted from 1 thematic work; 1 class, 11 lessons, 2 lessons quoted from

Table 10.4. Observational data.

selection of schools, classrooms, teachers, and pupils from whose activities the empirical material is generated. It seems to be important to distinguish between choices concerning $(a)$ all observations that are made in a project, $(b)$ the observations that are analysed for a certain study and $(c)$ the observations quoted in the presentation of the studies (here, the essays). Besides the observational data, other kinds of data are often used, such as educational materials, interviews, and questionnaires. A large amount of observational data gives certain opportunities, for instance when it comes to specific comparisons where many factors need to be almost the same to allow a certain factor of interest to be pin-pointed (for example, Kilhamn et al.; Osbeck). Thanks to rich data produced over time, it can also be possible to follow the development of communication patterns and the establishment of joint constructions of meaning (for example, Rocksén). The fact that the selection of data in several steps, as described above in $(a)-(c)$, can be understood as crucial in these studies, and imposes high demands on descriptions, arguments, and discussions of these selections. This can be a challenge.

The fact that the empirical material for classroom studies is often much larger than both the material analysed and directly referred to in a specific study, provides classroom studies with both background information and contextual descriptions, which are seldom available in, say, questionnaires and interview studies. How this kind of information 
is used varies. From the essays in this volume, it is possible to say that many authors have had access to much more information about the studies' contexts than is noted in these essays. To what extent this non-explicit information affected the researchers' selections and interpretations of data, is difficult to know. The fact that broader descriptions of the conditions and structures in the classroom are seldom referred to constitutes a weakness, for instance in relation to chances for the reader to generalise findings by drawing on contextual similarities (Larsson 2009). Perhaps better standards for how to conduct such contextual descriptions could be developed in didactic classroom studies. The issue can also be raised from other angles. If there is a great deal of information that is not being used in classroom studies, might it be possible to conduct better prepared, more directed empirical studies, so that less surplus information is produced? Or is a more extensive secondary analysis of existing material called for?

The kind of observation material that the studies draw on also varies. In the essays, the most frequent way of working with classroom observations is to use video recordings with several cameras in each classroom, complemented by audio recordings (for example, Sofkova Hashemi, Ingerman \& Booth, Hipkiss, Rocksén, Kilhamn et al.). The ways of analysing data are related to the available empirical information, which is not only a question of what observations are available, but also about how they are transcribed. Due to the detailed information that video studies have the potential to deliver, it is logical that many of the video-based studies choose to work with detailed communication analyses, where gestures and non-verbal communication are also taken into account. However, this is not always the case, and if so, the added value that detailed video recordings gives (for example in Kilhamn et al.) must be set against the risk to the authenticity of the classroom that is then created by the equipment. This is why field notes can be a preferred method for generating classroom data (for example, Lilja \& Claesson). None of the essays in this volume explicitly declare the methods used for transcription of the recordings-in the same way as the selection of material cited is important for the trustworthiness of the study, the ways of observing classroom events and of producing material for 
analysis from these notes or recordings impact the study's credibility (see also Sahlström 2008).

Just as the ways of generating data for analyses from observations vary between the essays, so do the methods for representing observations and analytical material. Despite the dominance of qualitative analyses of classroom events, the amount of data makes structuring and quantitative representations in the form of tables and figures useful (for example, Hipkiss, Kilhamn et al., Osbeck). Broader patterns become easier to identify. Analyses of classroom design allow plans of the classroom interiors to become central representations (Hipkiss) and the pupils' multimodal educational materials and their interpretations of these materials can be presented simultaneously using innovative tables (Sofkova Hashemi). Also, the transcriptions of the video recordings in the essays vary. In some essays, interpretative summaries of the exclusively visually communicated messages in the films are combined with the verbal quotes in the excerpts; in others, the authors have chosen to focus on the verbal communication and to put interpretative comments in separate text sections. Some data, both transcripts and field notes, are referred to as summarised narratives, both with and without quotations. Thus quotations from classroom observations are used differently depending on the essay, and are given different meanings by different authors. This means that the function of quoted empirical data in a given text - the claim made by quoting it - cannot be taken for granted, and is a key issue that needs to be communicated clearly.

\section{Didactical research specialisations}

This volume brings together a wide variety of didactical specialisations that the essays relate to: mathematics (Kullberg; Kilhamn et al.), first languages (Sofkova Hashemi), the sciences (Ingerman \& Booth, Rocksén), the social sciences (Osbeck), and general didactics (Hipkiss, Lilja \& Claesson). To what degree it is possible or meaningful to link a certain essay to a didactic specialisation varies. In mathematics education, for instance, it is not sufficient to relate the studies to mathematics education generally, but to the knowledge 
areas that the studies represent, for instance algebra (Kilhamn et al.) or multiplicative structures, the distributive law and the commutative law (Kullberg). This can also be said to be the case for the studies on science (Ingerman \& Booth, Rocksén) and first-language education (multimodal texts), while the social studies contribution in this volume has a broader focus ('Introduction to religious studies' and 'Current news'). The two essays that were understood here as contributions to general didactics do not relate to one single subject, but rather to a content interest and specific focuses (discipline and order-Lilja \& Claesson; classroom design-Hipkiss). The volume and specificity of previous research vary between different didactic specialisations. Also, the degree of agreement concerning what constitutes important knowledge to teach seems to differ between the research specialisations. The research fields have different conditions, and therefore different strategies for working in a qualified way in these fields must be applied. Didactics is not a single field, but a composite and rather diverse one.

In order to show how much didactical research fields can differ, two examples-religious education and science education-are given. In a Swedish context, religious education (RE) can be understood as a part of the social science education field together with geography, history and civics education. However, putting these four subjects together is a specifically Swedish curriculum construction, which means that the four fields are not necessarily closely related in international educational research. Unlike science education, the various fields must be dealt with separately.

Research in or related to RE is conducted in many different academic disciplines that primarily belong to religious studies, theology, or education. What unites RE research is an interest in institutions where teaching and learning about religion take place, in a Swedish context mainly school and church. This means that RE as an academic discipline in the Nordic countries has to a large extent developed in the faculties of theology (for example, Osbeck \& Lied 2012).

$\mathrm{RE}$ research, in connection to both schools and religious communities, works today with rather strong international networks both in the Nordic countries and worldwide. However, it can be problematic to compare and to learn from RE school studies conducted in other 
countries, since the differences in what one defines as RE content are so great (see for example, Schweitzer 2004). In many countries $\mathrm{RE}$ is confessional, and even in the Nordic countries there is no common understanding of RE as a school subject.

Swedish RE research has been described as lacking a body of research concerning teaching and learning processes in progress, for example classroom studies (for example, Kittelmann Flensner 2015), which also seems to be the case internationally (Osbeck 2012; Osbeck \& Lied 2012). Researchers have been more interested in prerequisites for teaching and learning, for instance concerning the aim of the subject, a disputed question since the 1960 s when the school subject was given its neutral, plural position. Pupils' existential perspectives, particularly the 'life questions' (livsfrågor) have been comparatively high on the agenda, as have textbook studies. Some evaluative studies do exist, of which several are related to the national evaluations commissioned by the Swedish National Agency for Education (for example, Jönsson \& Liljefors Persson 2006). Moreover, it should be mentioned that there is a large body of RE literature that focuses on research on religious studies per se, and which is considered important for RE teaching and teachers (Osbeck \& Lied 2012).

Unlike RE, science education is a highly internationalized field, constituted by a huge volume of work during the last 50 years, following the post-sputnik push for development of science education at all levels in the US, which spread across the world. This may be traced, for example, in the discussion of the notion of science literacy (Roberts 2007; Feinstein 2011), and articulations of the goals of science education. The dual focus on science for future scientists and science for all has been a major concern in this discussion. Traditionally, science education has been dominated by pupils' construals of conceptual and procedural knowledge, using individualised perspectives on learning. Later, the field has expanded to include, for example, issues of epistemology and affective factors (such as pupils' perceptions of science and scientists) (Roth 2010), as well as issues of culture, gender, and society, and these now constitute major parts of the field (Lederman \& Abell 2014).

That the didactical fields vary when it comes to available research 
can also be shown through a couple of examples from the Swedish database Swepub. While in September 2017 the keywords 'science education' brought up 690 peer-reviewed contributions, a similar search for 'religious education' results in 107 contributions.

However how well developed, rich, and specific a research field might be, it has consequences for the research quality that can be achieved in certain areas. If the state of the art is vague, unclear, or non-existent, the focus of new research studies is of necessity less directed and specific; a new study has less to draw on, competing research patterns or scientific debate is absent, while the dependence on the subject discipline, on general educational research, and other didactical specialisations increases.

That the didactical research field varies in breadth and specificity is also shown in the essays in this volume, for instance in their references. In addition, the reference lists show a variety in degree of internationalization. Some subjects are more international and not very culturally dependent, whereas other areas such as language, literature, history, or political science are more bound to a specific country. At the same time, the possibility for international comparisons is an issue that could be considered more generally. To what extent are the patterns of findings referred to as 'previous research' comparable to one another and to findings from a Swedish classroom study? To what degree is it possible to compare findings from the studies that are cited? Is there a risk that the use of English as a common language hides the fact that we are researching different phenomena?

Unlike some claims concerning didactical research, the studies in this volume are constituted independently from curricular regulations (for example, Dahlin 1989; Scherp \& Scherp 2002). Three of the essays do not refer to the curriculum at all, and the others only touch on it briefly. The relationship with curricula is briefly discussed by Kilhamn et al., who call for caution when comparing classroom processes, since the contexts and curriculum regulations vary greatly. The normative function of curricula can also be assumed to be harder to apply in international comparative classroom studies, where instead the teaching and learning processes can be understood as enacted curricula. 


\section{Knowledge claims}

Naturally enough, the knowledge claims in the essays are closely related to the aims and research questions (See Table 10.2 above). This means that there is an interest in developing knowledge concerning several of the factors in didactic classroom teaching, since they can be understood as interrelated. In our overview, we have raised the question of whether there might be a potential for development in didactic classroom studies, when it comes to paying attention to the classroom conditions and structures, avoiding treating the classroom as simply a location where teaching takes place, and instead studying how it conditions interaction and in that sense impacts teaching and learning, as Hipkiss, for example, shows. A broader interest in conditions and structures may have the potential for important findings concerning teaching and learning processes in the classroom.

The aims and research questions of the essays result in knowledge claims that can be understood on a variety of levels. Several of the essays make on the one hand claims concerning the specific phenomena and classrooms studied, and also on the other hand broader knowledge claims concerning the phenomenon of which the case study is an example. In Kullberg and Skodras's essay, for example, there is a knowledge claim concerning what was possible for the pupils in the specific classrooms to see when using Muffles' set of examples in multiplication. However, there is also a knowledge claim concerning the systematic variations of examples in teaching as a powerful way to help pupils identify certain phenomena-a knowledge claim that has the contours of a law of a more generic character.

The double knowledge claims, directed at different levels, reflect the fact that classroom studies make validity claims outside the specific empirical context, despite their qualitative case-study format. This broader claim is not always spelled out explicitly, since the grounds for claiming a specific range of validity is not well established for these kinds of studies. In the example used here, we do not see it as problematic to generalise due to the solid theoretical grounding, with research patterns from other previous studies backing up the findings.

The possibility of making broader claims on the basis of didactic 
classroom studies is key in order to make progress in the field, and to contribute to it systematically and accumulatively. It is reasonable that research should give information that is relevant beyond the specific case studied. Therefore, important directions for didactic classroom studies can be as follows. First, identify when it is possible and reasonable to make broader knowledge claims and generalise from the studies and when not. Second, didactic classroom studies would benefit from systematic, explicit attention being paid to the range of validity for the claims made. And third, summarise general patterns in condensed conceptual terms, and so contribute to further theoretical development in the didactical arena by providing concepts for further analyses (see, for example, Ingerman \& Booth).

Didactic classroom studies typically examine contextual 'wholes' of classroom events (Svensson 2016). This implies that controlled, statistical generalisation is not available for claims to a range of validity. As Svensson $(2016,283)$ notes, 'The openness and uncertainty of descriptions, due to the context-dependent nature and complexity of human and social phenomena, cannot be solved by denial of this character. The traditional escape from the problem to abstract predefined concepts, categories, and variables, and to statistical generalisations, is no solution, and only gives weaker and more uncertain evidence than case-based descriptions have the potential to give.' Thus, it is of limited value to attempt to define a definite range of validity for the knowledge claims in didactic classroom studies. Important aspects of the generalisation will depend on close contextual analysis of the original empirical situation, and comparisons with other situations.

It may be helpful to systematically discuss the potentials that are relevant for knowledge claims rather than the extent to which they are generalisable. Collier-Reed et al. (2009) identified three kinds of potential: collective, critical, and performative. Collective learning potential is the traditional value for contributing to the systematic and collective building of a body of research emanating from, in this case, the research direction. In critical potential the relevance comes from the identification and making visible of an aspect or phenomenon which in a potential range of situations is of importance or in some way problematic-here a single case can give a great deal of 
leverage. Performative potential, meanwhile, points to innovative relevance, generating new possibilities of didactical action in other classrooms. Several of the essays have strong characteristics of this kind of potential, in that they point to alternative sets of action in the classroom, facilitating change built on research. Here it is important to reflect on the conditions and consequences of realising such performative potential, as change also may take us in unexpected, and even unwanted, directions, especially concerning the contextually very sensitive classroom arena.

A prerequisite for all three kinds of potential regarding the relevance of knowledge claims is a close connection between the empirical case being studied and relevant previous research. Having such a body of previous research to draw on means the researcher must take responsibility for its further development. It is important to point out how certain findings and knowledge claims relate to the extant body of research, and to warn of the limits of the findings and what further research is indicated by the present findings and their limitations.

Research also leads to the discovery of unexpected things, of course. Therefore, it is of great importance to make room for these kinds of findings. To count on unforeseen findings is also a perspective close to the nature of classroom processes and teaching itself. Several of the essays in this volume show that it is the unpredictable utterances of pupils that make it possible for teachers to clarify patterns and statements that theoretically should have been possible for the pupils to understand, but nevertheless were not fully grasped. It is one task of didactic classroom studies to show the unpredictable nature of classroom interaction, and in that sense also the greatness in human interaction and teaching. It is therefore important to develop research designs that have the potential to capture and show this, and allow the possibility of unforeseen findings becoming central knowledge claims.

\section{Didactical consequences}

The essays' findings can be considered as important for practice-as having didactical consequences for teaching and learning, both specifically and regarding more general insights. However, to what 
extent and in what way the essays set out to directly contribute to practice and development varies. Indeed, at least four ways can be identified.

First, classroom studies can be designed to try out methods and approaches that one has reason to believe can be effective. Kullberg and Skodras's essay can be seen as an example of such a study, where the effects of a systematic variation in examples are tried out. Second, classroom studies can contribute to practice and teachers' awareness using approaches where teachers' interpretation of practice and development of practice are part of the research. The teachers increase their knowledge through observations, reflections, and discussions with other teachers and researchers, and the research insights generated in such a way may also be of value, thanks to the teachers' knowledge of these practices. The study presented by Kilhamn et al. is an example of such a design. Third, classroom studies may be designed with the purpose of studying what one has reason to believe to be good practice. It is not clear if there are such studies in these essays; it is not explicitly declared to be the case, but on the other hand, we know that it is quite usual that teachers that are known to be particularly skilled are asked to participate in classroom studies. Fourth, and this applies to the majority of the essays in this volume, classroom studies have an ambition to reveal mechanisms that can be understood as especially favourable-but also particularly unfavourable-when it comes to pupils' opportunities to attain their educational goals.

It is common in educational research to avoid being explicit about what consequences the research may have for practice. A variation of such a standpoint can be seen in Rocksén's essay, where she stresses that the essay should not be understood as an attempt to prescribe teaching practices, since 'the development and evaluation of best teaching practices is primarily a task for the teaching profession.' This is an important statement that reflects respect for teaching as a profession on its own terms, in line with the general tenor of didactics. However, one could also say that the researcher is likely to be the person best placed to interpret the findings and their meanings. From such a perspective, one could consider it to 
be the researcher's responsibility to interpret the findings in terms of didactical consequences. It is not unlikely that differences in opinions on research implications for practice concern how one interprets the task. To interpret and discuss possible consequences of reported findings is not necessarily to prescribe what constitutes best teaching practice.

It is not possible to summarise the didactical consequences that have been emphasized in the different essays in a specific way. On a more general level, the implications mainly concern the centrality of teachers' and pupils' collective directedness towards learning objects, as well as stressing the importance of clarifying learning objects, and of teachers' awareness and knowledge concerning phenomena that are known to be of importance in order to enhance pupils' learning. The implications also concern teachers' communicative skills, such as their ability to grasp pupils' perspectives and to respond in ways that support the development of pupils' understanding over time. Classroom activities are shown to be complicated activities where different actors and factors can thwart one another's effects, but also compensate for each other's shortcomings, as long as one is aware of aims, available resources, and how to use them. Classroom studies may enhance our collective awareness about these factors and thus have didactical consequences.

\section{Research ethics}

The importance of conducting research in an ethically responsible way cannot be stressed enough. Classroom research faces several distinct challenges, among others things due to the close relations that can develop between the researcher and the participants. That means that ethical concerns unavoidably permeate the whole research process. All acts have consequences for others and ethics is about being aware of the power that is linked to that fact, being sensitive to what happens, and responding in wise ways (Kang \& Glassman 2010; Løgstrup 1997). A difficulty in classroom research concerns unequal relations of various kinds and levels, which is an argument for caution. At the same time can this ethically caring approach be 
hard to combine with the critical gaze that educational research demands. However, the close relationship between research and teaching practice means possibilities for development and learning from each other, if difficulties can be addressed and shared in a mutually open and trusting manner. For instance, principles for research ethics-informed consent; 'voice' and ownership; transparency and negotiation; confidentiality, anonymity and trust-have been suggested as tools for both parties to meet around, and in response to which to develop both research and teaching practices (Mockler 2013). The closeness in relationships that characterizes classroom research also increases the opportunities for trust to develop; this in itself can hinder the unfruitful 'teacher bashing' that educational research has sometimes entailed (Dudley-Marling 2005).

Another kind of ethical difficulty that classroom studies struggle with is the protection of individual integrity when working with video recordings. Similarly, the non-controlled, thematic focus of classroom studies constitutes an ethical challenge since there is the risk that it will unintentionally generate sensitive personal data if the pupils happen to make statements about racial or ethnic origins, political opinions, religious or philosophical beliefs, health or sex life. It is of great importance to be well aware of laws and regulations concerning research ethics, even if this can never replace being ethically reflective concerning events that are not regulated but nevertheless demand responsible treatment.

Dealing more fully with the issues of research ethics and classroom studies lies outside the scope of this essay. Here, a few brief comments will be made in relation to the essays in this volume. First, it must be considered a challenge that it has not yet become a routine in each and every study to explicitly pay attention to research ethics-to demonstrate how ethical responsibility has guided the project and has been safeguarded. Second, the issue of confidentiality goes far beyond what is usually reflected in these kinds of studies. It seems to be relevant to distinguish between the confidentiality that it is possible to uphold outside a current practice and inside this practice. Confidentiality inside the practice is almost impossible to achieve. It is likely that the whole school will know that a teacher who is being 
filmed with mounted cameras is participating in a research study. It is important to be frank about this, and to discuss the possible implications. Third, the possibility of placing non-participating pupils in non-filmed areas of the classroom is not as uncomplicated as it may seem at first glance, and as is sometimes suggested. If the research is informed by a learning perspective where meaning is collectively constructed, it is very hard to remove voices or let certain collective events go unnoticed. It is neither an authentic nor a responsible way to work. Fourth, a specific challenge concerns the sort of studies that work with interventions in practice. As Burner (2016), for example, has discussed, it raises questions about who owns the process and who owns the responsibility for its effects.

Research ethics issues have been more on the agenda lately, especially since the Swedish Act concerning the Ethical Review of Research Involving Humans (SFS 2003:460) was passed. It is reasonable to assume that this can be considered a first step for an intensified discussion to come. We consider such a development an important direction for didactic classroom studies.

\section{Didactic classroom studies- constitution, conditions, continuation}

The purpose of this essay has been to investigate the variations and commonalities across the contributions, the emerging potential research direction didactic classroom studies, and with such an investigation as a basis, to formulate suggestions for further developments for this research direction. The descriptions and discussions have showed some of the ways these studies are constituted and conditioned. It has also pointed to a potential continuation, in which the research direction becomes more established. This has been done through identifying challenges and discussing possible ways to address them. These further steps are summarised here.

As suggested in the introduction, the analyses have showed how didactic classroom studies largely combine focuses on teachers, pupils, and content. However, this can also bring a dilemma. Observing and showing that a multitude of aspects and factors are at stake, 
influencing teaching and learning processes, might mean a challenge in limiting the analyses and keeping to the aim of the study. At the same time, the analyses of the essays show how broader contextual research perspectives that focus on conditions and structures are not that usual. These observations raise an awareness of the potential importance of working with frameworks that can combine broad structural and contextual perspectives with a sharp focus on specific aspects of the teaching and learning processes of interest.

The importance of an acute awareness of available and possible theoretical frameworks, and their strengths and weaknesses for developing didactical knowledge further, is also shown. The framework is of great importance for a consistent and cumulative knowledge production, and a central question is to what field a study contributes by applying a certain framework. For the type of classroom studies exemplified here, another key issue is how the combination of theoretical and empirical perspectives is constituted in the analytical frameworks that are actually put to work. As argued throughout this essay, a focus on didactical consequences needs to be at the core of didactic studies. A theoretical framework must help in this work if it is to be fruitful.

The essays of the volume show a great variety in empirical designs. However, the issue of empirical design is not something to consider in isolation, but instead must be related to other aspects of the classroom study. The composition of different parts of a classroom study and the way these are represented in the final text constitutes a whole. The way of representing data, composing the report and writing it, creates in itself trustworthiness. Such trustworthiness presupposes an explicitness about the selection of data to be analysed as well as about the chosen excerpts referred to. The selection of data is made in several steps, which can be seen as crucial for and characteristic of classroom studies, which often work with plenty of data. How the selections are linked to the claims is of course central. Classroom studies give unique opportunities through their production of background information about pupils, teachers and the wider context. An important question concerns how one makes use of this information in a transparent, aware and critical sense so 
that the advantages of these studies and the information they deliver can be used optimally.

The exemplifications of didactical research specialisations and their traditions in this volume and this essay makes clear that didactics is not a single field but rather a multifaceted one. The specialisations have different histories, traditions and current conditions, which have consequences for what it is possible to do and achieve through classroom studies. For instance, the degree of internationalization of these fields and the volume of previous research vary. How research is conducted in powerful ways in fields where available relevant research is largely lacking is an important issue to consider further. At any rate, independently of how large the body of available research is, the issue of what is comparable and to what extent previous studies can be drawn upon-for example, those conducted in other countries where education may have rather different regulations-is a central one.

That the knowledge claims of the studies were not specifically concerned with the conditions and structures for teaching and learning processes in the classroom may be of interest in follow-up analyses of other classroom studies. Moreover, the essays show that the knowledge claims vary concerning how specific or general they are. It seems to be important for the development of the field and the knowledge production that the studies are constructed in such ways that it is possible to also draw wider conclusions from a study than those that only concern the single classroom. Clarity concerning what constitutes a case is central, as for the conditions for when broader claims can be made on solid foundations, which needs further attention. The relation between an empirical study, its theoretical framework, and available relevant previous studies should be evident, as well as the importance of encouraging and directing the further research that can be expected on the basis of the presented findings.

That didactical consequences of classrooms studies for practice can take different forms and be interpreted in different ways, is shown by the contributions in this volume. Arguing for the importance of didactical implications of classroom studies, stressing that a 
researcher's interpretations and discussions of the possible implications of reported findings for practice is a central knowledge contribution, is not the same as saying that he or she also should prescribe what constitutes best teaching practice. In this volume, didactical consequences of the presented classroom studies can on an overarching level be understood as enhancing collective awareness about factors that are known to be of importance in facilitating pupils' content learning but also about those known to constrain it. The different essays give different concrete examples of this. In this sense, this volume is not only a contribution to research, but also an offering to practice, to the everyday life of teachers and pupilssomething which also can be said to characterize didactic classroom studies. To have the opportunity to contribute in such a process is a joy and a privilege for us as didactic classroom researchers.

The privilege of conducting classroom research must be managed with care. How to protect the integrity and interest of the participants while at the same time providing qualified and authentic knowledge about teaching and learning in the classroom is one of the most fundamental questions of research ethics. It is a crucial issue for further possibilities for conducting these sorts of studies. Therefore, it is of the utmost importance for the development of the field, for the direction of further research, that the researchers, in addition to their knowledge of the frameworks, develop ethical sensitivity in terms of identifying ethically critical aspects and finding ways to deal with them. The increasing demands to explicitly address and demonstrate how an ethical responsibility has guided the project and been safeguarded is therefore to be welcomed. To be skilled in research ethics is not only a necessity for members of ethical review boards. It is a part of what it means to be a qualified empirical researcher, a researcher in didactic classroom studies.

The ambition of this volume has been to bring didactic classroom studies together and in that sense to present research of a high standard, and to make the collective challenges visible. This essay, with its condensed presentations of the essays' variations and commonalities, and thus its presentation of challenges, has aimed at contributing to the way forward-a potential research direction-for the field. In 
this way, we hope that this is not the end, but rather a starting point for further developments of this project. The importance of further discussions and improvements to didactic classroom studies is an urgent issue-for research as well as practice.

\section{References}

Burner, T. (2016), 'Ethical dimensions when intervening in classroom research', Problems of Education in the 21St Century, 73, 18-26.

Collier-Reed, B. I., Å. Ingerman \& A. Berglund (2009), 'Reflections on trustworthiness in phenomenographic research: Recognising purpose, context and change in the process of research', Education as Change, 13/2, 339-55.

Dahlin, B. (1989), Religionen, själen och livets mening (Gothenburg: Acta universitatis Gothoburgensis).

Dudley-Marling, C. (2005), 'Disrespecting Teachers: Troubling Developments in Reading Instruction', English Education, 37/4, 272-9.

Englund, T. \& G. Svingby (1986), Didaktik och läroplansteori', in F. Marton (ed.), Fackdidaktik (Lund: Studentlitteratur).

Feinstein, N. (2011), 'Salvaging science literacy', Science Education, 95/1, 168-85. Freeman, S., S. L. Eddy, M. McDonough, M. K. Smith, N. Okoroafor, H. Jord \& M. P. Wenderoth (2014), Active learning increases student performance in science, engineering, and mathematics', Proceedings of the National Academy of Sciences, 111/23, 8410-15.

Hattie, J. (2009), Visible learning: A synthesis of over 800 meta-analyses relating to achievement (London: Routledge).

Hopmann, S. (2007), 'Restrained Teaching: The common core of Didaktik', European Educational Research Journal, 6/2, 109-24.

Hudson, B. (2007), 'Comparing Different Traditions of Teaching and Learning: What Can We Learn about Teaching and Learning?' European Educational Research Journal, 6/2, 135-46.

Ingerman, Å. \& P. O. Wickman (2015), 'Towards a teachers' professional discipline: Shared responsibility for didactic models in research and practice, in P. Burnard, B.-M. Apelgren \& N. Cabaroglu (eds.), Transformative Teacher Research: Theory and Practice for the C21st (Rotterdam: Sense).

Jönsson, R. \& B. Liljefors Persson (2006), Religionskunskapi årskurs 9-Rapport från den nationella utvärderingen av grundskolan 2003 (NUo3)-Samhällsorienterande ämnen (Malmö: Malmö Högskola).

Kang, M. J. \& M. Glassman (2010), 'Moral Action as Social Capital, Moral Thought as Cultural Capital', Journal of Moral Education, 39/1, 21-36. 
Kittelmann Flensner, K. (2015), Religious education in contemporary pluralistic Sweden (Gothenburg: Göteborgs universitet).

Klette, K. (2007), 'Trends in Research on Teaching and Learning in Schools: Didactics Meets Classroom Studies', European Educational Research Journal, $6 / 2,147-60$.

Larsson, S. (2009) 'A pluralist view of generalization in qualitative research', International Journal of Research \& Method in Education, 32/1, 25-38.

Lederman, N. G. \& S. K. Abell (2014) (eds.), Handbook of research on science education, ii (New York: Routledge).

Lindmark, T. (2013), Samhällskunskapslärares ämneskonceptioner (Umeå: Umeå Universitet).

Løgstrup, K. E. (1997), The Ethical Demand (Notre Dame: University of Notre Dame Press).

Mockler, N. (2014), "When "research ethics" become "everyday ethics": The intersection of inquiry and practice in practitioner research', Educational Action Research, 22/2, 146-58.

Öhman, J. (2014), 'Om didaktikens möjligheter: Ett pragmatiskt perspektiv', Utbildning \& Demokrati, 23/3, 33-52.

Osbeck, C. (2011), 'Religionsdidaktik som kunskaps- och forskningsfält', in M. Löfstedt (ed.), Religionsdidaktik: Mångfald, livsfrågor och etik (Lund: Studentlitteratur).

Osbeck, C. \& S. Lied (2012), Religionsdidaktisk arbeid pågår! Religionsdidaktikk i Hamar og Karlstad (Vallset: Oplandske Bokforlag).

Roberts, D. A. (2007), 'Scientific literacy/science literacy', in S.K. Abell \& N.G. Lederman (eds.), Handbook of research on science education, i (Mahwah, NJ: Lawrence Erlbaum Associates).

Roth, W.-M. (2010) (ed.), Re/structuring science education: Reuniting sociological and psychological perspectives (New York: Springer).

Sahlström, F. (2008), Från lärare till elever, från undervisning till lärande: Utvecklingslinjer i svensk, nordisk och internationell klassrumsforskning (Stockholm: Vetenskapsrådet).

Scherp, H.-Å. \& G.-B. Scherp (2002), Elevers lärmiljö: Lärares undervisning och elevers lärande (Karlstad: Karlstads universitet).

Svensson, L. (2016), 'Towards an integration of research on teaching and learning', Scandinavian Journal of Educational Research, 60/3, 272-85. 